\title{
The New Industrial Strategy in a Context of Financial Contraction in Algeria
}

\author{
Chaib Baghdad ${ }^{1}$, Rachedi Abdelkader ${ }^{2}$ \\ ${ }^{1}$ Faculty of Economics, Laboratory of Money and Financial Markets in the Maghreb, University of Tlemcen, Tlemcen, Algeria \\ ${ }^{2}$ Faculty of Economics, University of Saida, Saida, Algeria
}

Email address:

chaibbaghdad@yahoo.fr (C. Baghdad),arachedi@gmail.com (R. Abdelkader)

\section{To cite this article:}

Chaib Baghdad, Rachedi Abdelkader. The New Industrial Strategy in a Context of Financial Contraction in Algeria. International Journal of Economic Behavior and Organization. Vol. 9, No. 2, 2021, pp. 27-35. doi: 10.11648/j.ijebo.20210902.11

Received: March 29, 2021; Accepted: May 12, 2021; Published: June 7, 2021

\begin{abstract}
Industrial development has gained a position of strength in the successive debates on the realization of economic development projects, accentuated by exceptional progress of new technologies, such as innovation, creativity and entrepreneurship, with a tremendous growth of more innovative companies in terms of production, service delivery or simply concentrated on resell. One can, of course, invoke innumerable theoretical and literary arguments about the contribution of the industrial sector in the economic growth, starting from the works and approaches of the classics and neo-classics, particularly the most contemporary ones, like Rosenstein-Rodan, Myrdal, Nurkse, Hirschman, and many others, as long as the debate focused on the means and instruments to benefit States, provided that it is well managed. Algeria has been well engaged in the implementation of an industrialization strategy, through some programs and projects of revival of the industrial apparatus, in particular the model, globally recognized," industrializing industries" in order to find alternatives for import substitution and the establishment of an industrial platform capable of raising the level of economic development upwards, and above. Indeed, industrial policy has become hostage of energy and hydrocarbon policy, as long as all investments and efforts have been made and directed in the promotion of the extractive industries, since the oil markets have created opportunities an for financing economic projects, leaving behind other components of the industrial sector, especially manufacturing industries. Taking this into account and in another effort to break away from the grip of the oil sector, the Algerian State turned to a new industrial policy and strategy, which will be more interested in the promotion of manufacturing industries, but this becomes relatively complicated and delicate, in view of the deterioration of public revenues and the possibility of drying up of revenues, as a consequence of the fall in oil prices, leaving, thus, puzzled economic decision-makers on the appropriate means of financing and accompanying this step. We will try, through this paper, to examine the planned and tracked modalities for such a large project, given the economic and financial context, which calls for greater prudence and the rationalization of public expenditures and their targeting.
\end{abstract}

Keywords: Industrial Strategy, Energy, Algeria, Financing, State, Conjuncture, Development

\section{Introduction}

Some literary and conceptual approaches to the place of the industrial sector in economic development

The role played by this sector in the issues of development and economic growth is highly recognized and valued by $\mathrm{u}$ number of economists, because it would be an offense and contempt for the tremendous contributions and involvement of industry in this sense, being convinced that the formidable the industrial and technological revolution, that began in the mid-1800s in the booming and euphoric era of the classical economy, transformed, radically and globally, the entire structure of the world economy, with positive and advantageous effects on production, productivity and economies of scale.

Therefore, it will be pointless to justify more about the place of this sector in the development of the international economy, but rather more judicious and appropriate to cite some approaches and theoretical arguments to this question, a way of consolidating and strengthening our position and to recognize that industry is well behind the remarkable 
economic performance of national economies without, of course, diminishing or narrowing the contributions of the agricultural sector and services.

In this paper, we will be content with a few interventions, starting with J. A. ROBINSON which states that "The different choices of industrial policy, their successes or failures, are less to be attributed to ideas or economists, even though they may play an important role in certain particular cases, but more to the nature of the political balance in society" [7], suggesting that the contribution of the industrial sector in a growth dynamic is more centered and dependent on the nature of each economy, taking into account the possible and expected interests and possible consequences.

Attempting a more comparative approach, this author proposes some ways and alternatives to understand how the industry can reach a stage of promotion, like:

1) More pronounced strengthening of the policy already in place.

2) Possibility of institutional change (if necessary).

3) Political balance.

Remaining in this logic, and as quoted by G. RAVEAUD), D. RODRIK (2009), despite some critics, insists that industrial policy is more appropriate and adequate to promote and revive a dynamic of economic development, arguing that these policies "will fuel an internal demand that will offset the decline in external demand" [6] provided that economic decision-makers, primarily the State, are more involved in choosing the most appropriate approaches and initiatives to such policy, mainly tariff, fiscal and regulatory choices, in order to better play the public-private partnership card, while keeping the benefits of the policy's impact on the various stakeholders.

The author (G. RAVEAUD) reconfirms the idea that "History shows indeed that, in the North as in the South, public investments and policies of orientation of the private investments are necessary conditions for the development"[6].

A number of readings teach us that the debate on industrial policy is brought back into the benefits and gains that can be made and unearthed from this policy, not just for the benefit of the sector itself, but for the entire economy and this through some implications as follows:

1. Training effects on other productive sectors.

2. More job creation.

3. More incentives to innovation and technological creations.

4. Probable attractiveness of foreign investment.

5. Strengthening technological leadership.

6. Strengthening position and competitive competitiveness.

7. More sustained and sustained economic growth.

In another note, it is clearly stated that "it is not very difficult to demonstrate that industrialization is a strategy for reducing poverty: whether it be European countries, the United States or Japan., or of those who caught up with them in the second half of the 20th century, including the Republic of Korea, China and the many other "tigers" and "dragons" of
Asia, it is in all cases the industrial development and trade in industrial goods that have allowed the success of each other" [11], a finding that can be described as official and less surprising, but which remains a reality well endorsed and defended by leading economists and experts.

In another approach developed by A. ALBERT and M. A. CRENER [1], it is a question of an attempt to explain industrial development by means of endogenous and exogenous parameters, in order to better understand the contribution of the industrial sector in the economic development of two emerging countries, namely South Korea and Brazil, while warning that the emergence of robotics and telematics can modify existing structures and direct research to other sources and niches that may, eventually, become more complicated and tricky for some economies that have failed to achieve favorable and appropriate conditions, especially human capital, research and development functions.

This allows us to better consider the place of the sector in issues related to economic development, far from all insinuations, subjective and flat approaches, and with a view to placing a more critical and conventional view on this issue, especially when many approaches reaffirm and insist that the industrial technology sector is the only spearhead and stimulus of the international economy, at a time when other sectors seem to be stalling and have difficulty producing the growth effects for this economy, like the agriculture and services that await a dynamic of the global industry to be able to integrate and get involved in this approach, especially as the experiments have shown that the implementation and in innovation technologies and techniques are more applied and maintained in the industry than others.

This is corroborated by other interventions and implications of authors who have shown that industrial development is synonymous with economic development, through the many benefits acquired, such as employment, value added, availability of goods and industrial goods, the effects of sequencing and training of other sectors and economic activities, the dynamics of economic enterprises, especially small and medium-sized enterprises, economies of scale, and others, confirming that debate on the relationship between this sector and the issue of economic development leaves no room for doubt as to proven veracity.

In another conceptual approach, it is clearly stated that "Industry retains a crucial role as a locomotive in the economy. Through its intermediate consumption (the products it uses in its production processes), it often works in many other sectors" [10], proving, once again, the arguments that justify and applaud the convergence in this certainty which, despite some speeches distilled here and there on a confirmed deindustrialization, the fact remains that this activity is more promising for long-term economic growth, in conditions and contexts that do not contribute too much in this respect., given the strong turbulence observed and noted during the last decades.

With the exception of the energy industry, several international economies have focused their efforts to 
modernize the manufacturing industry, as it has propelled itself into international trade and has led to substantial gains in manufacturing, terms of trade and a flattering and imposing repositioning in international trade.

In a previous report, it is clear that the manufacturing industry (which remains just a part of the industrial sector) is a decisive factor in world employment and its role remains essential and fundamental according to some remarks as follows (according to this organization):

The manufacturing industry, which employed about 470 million jobs in 2009, one in six jobs worldwide, remains crucial for job creation. It probably exceeded half a billion jobs in 2013.

Least developed countries have immense potential for industrialization in food and beverage products (food industry), textiles and clothing. These industries offer good prospects for both sustained job creation and productivity growth.

In all countries, industrialization not only increases the number but also the quality of jobs.

, Therefore, the industrial sector proves our interest and attention, not only for this paper, but in an international dimension, supported, it must be emphasized, by the relevant and confirmed theoretical and conceptual interventions, as well as the conclusions and syntheses of several reports, thereby reinforcing our course of action so that we can examine and analyze this sector in the case of the Algerian economy, trying not to focus solely on energy, and pointing our focus to the other components of the sector, especially the manufacturing sector.

\section{Method: A Look at the Industrial Sector in Algeria}

The discussion on this sector can extend and widen longer and even if it exist other more interesting explanations, but it must imperatively pass through an inventory, in our concern to initiate an objective and relevant examination, especially since 1970 .

It must be said that this sector has experienced two contrasting periods: A first that has been characterized and distinguished by a phenomenal infatuation and seizing economic decision-makers, through the various investment programs devoted to it, an average of 40 to $50 \%$ during the first economic plans (1967, 1970, 1974, 1980, 1985 and others), resulting, therefore, on a contribution in the national GDP foiling with an average of $35 \%$ during these decades, and a second that has saw a dangerous and worrying decline, with a contribution rate in the national product of only $5 \%$, especially for non-hydrocarbon industries, and manufacturing specifically.

Beyond the figures and data available, it should be made clear that since the decision to nationalize the oil sector in 1971 and the implementation of the model industrializing industries of Debernis, the Algerian State has forged a tactical idea appropriate for the sector, through the following functions:

1. A stronger contribution to economic growth.

2. The creation of training effects on the other productive sectors.

3. The exploitation of hydrocarbons (oil and gas), not only as providers of revenue and income, but also in the start-up and operation of the productive apparatus.

4. The production of an added value essential and necessary for the national economy.

5. Promotion of foreign trade, including the improvement of the terms of trade.

6. A more prominent and consequent role in the abandonment of the colonial economic and industrial system and the revival of a sovereign and independent economy (and industry).

Through an adequate and consistent industrial policy, there was talk of the emergence of a strong and consistent sector in order to focus on the achievement of certain macroeconomic objectives, especially the employment and wage, the model was schematized according to the doctrine of centralized and directed economies, and also in the interests of security and prudence in the face of the volatility of international markets and the threats of more developed countries.

A great deal of work and research was devoted to this theme, of which A. BOUZIDI made it clear that "the industrialization which the planners decided to implement in the early 1970s (first four-year plan 1970-1973) was aimed to build "basic industrial complexes" whose central core from which all the dynamics had to start is the steel industry" [2], confirming, thus, that the whole industrial strategy drew its dynamism, performance and financing of the level of development of the latter.

According to A. MEBTOUL, the choice of a national strategy for economic development, particularly in the industrial sector, is explained by the fact that this development can only result from a structural transformation, technical, economic, and social, transformations that require a strong implication of a consequent industrialization, and a strong presence of the State as the only guarantor of the mastery (and probable success) of this optics, while waiting for the revival of other sectors, and more specifically, the agricultural sector. [3]

Other economists interested in the analysis of this economy, like C. PALLOIX, P. JAQUEMONT, M. RAFFINOT, C. BOBROWSKI, converged on the idea that this industrial option, developed and adopted by the power in place, should allow a significant expansion of the productive forces, through the development of the workforce, because for the Algerian state, the time had come to break, permanently, with this state of under -development, which is identified more as a product of imperialism and colonialism, and to establish a genuine developmental approach, inspired and conceived more as a result of the struggles against the phenomena of spoliation and foreign domination.

Taking advantage of its strength and dynamism in the energy sector, the Algerian industry wanted to be part of an option to regain the hydrocarbon market, particularly after 
joining OPEC, with the aim of providing insurance and security against possible slippages and distortions in oil prices, a product that is too much in demand in international markets, while trying to maintain some cohesion and synergy between the other components of the sector.

Thus, the energy sector had to contribute on several fronts, in addition to provide financial means necessary for the continuation of projects selected under development plan and programs, such as:

1. As a supplier of energy necessary and useful for the operation of projects (as factor of production).

2. As a recruiter of the local workforce, for the needs expressed for such a factor of production.

3. As a participant in the different stages of the production process, applied by multiple economic enterprises, and contributing greatly in the creation of added value for the country.

4. As a skilled, competent and experienced trainer in matters relating to strengthening national and international economic competitiveness.

5. As a guarantee for foreign partners, with a view to improving the business climate.

6. As a guarantor of the economic, social and even political stability of the country, in a particular context experienced by it, namely the desire to get rid of the after-effects of the past and to weave other relations and links with other economic, financial and commercial partners.

It is also added that the interest granted by the Algerian State to the industrial sector (and more particularly that of hydrocarbons) is explained by the sovereignty acquired in the oil and gas sector, and the availability of a favorable political environment, for a first and priority recovery of the industry, to start a macroeconomic recovery that will encompass all active and dynamic sectors of the national economy.

The dominance of the industry, during this phase, remains clearly palpable, given the large shares allocated to it in the distribution of investments and bank credits, not to mention the growing and valuable interest of national (and even international institutions) for this type of sector and economic activity, considered as an asset and unavoidable potentiality for the revival of the economic machine of the country, in the absence of other sectors that cannot compete with and compete with other nations.

This question is perfectly illustrated by A. BOUYAKOUB when he states that "the industrial sector is experiencing a steady fall in production in all industries. With the exception of the energy and hydrocarbon sectors, which have steadily increased, all other sectors have suffered, at different levels, significant rates of decline" [4]. Thus, overall, the level of industrial production reached in December 1999 represents only $74.8 \%$ of that of 1989 . After more than ten years, industrial production has fallen by more than $25 \%$ where hydrocarbons has grown by $22 \%$, thus announcing the beginning of the decline of this sector, at a time when the world industry is seeking another reintegration within the real economy.
At a time when the international industrial sector, boosted and revived by new industrial technologies and innovation, attempts a breakthrough and immersion in issues related to economic development and growth, it dies and torments itself in the national economy as a result of a deindustrialization policy pursued since the structural adjustment programs and the privatization and industrial restructuring operations.

As is widely confirmed, the industrial sector has become bogged down in a stated priority towards the energy sector and a beginning of neglect of other industries, especially the manufacturing industry, pretending to recognize the weight that this type of industry, especially for the Algerian case, may have for the questions of employment, added value, trade and sectorial growth, and especially the prospects for training on other sectors of the real market economy.

This author concludes this well, saying, once again, that "These data (on the industrial sector) show that there are three types of sectors. Sectors that have experienced a positive evolution such as hydrocarbons and energy and especially the production of electricity. The second group of sectors concerns activities that saw a slight decline, such as agro-food industries, chemical industries and pharmaceuticals, and building materials industries. The third group is heavy industry, which has experienced a fall of more than $40 \%$, and finally manufacturing industries, such as textiles and leather, which have experienced a veritable collapse of their production, "denouncing, for example, a degree of bias and a well-supported bias of the economic decision-makers towards the hydrocarbons sector, perhaps in a spirit of focusing on the development of the latter so as to be able to start the process of development of other vital sectors for the national economy, a step which unfortunately, has dedicated itself as a failure.

The new industrial policy: Another policy or real opportunity of revival?

The new strategy of economic openness, as initiated by the Algerian State, has introduced a certain transformation of economic policy, now based on appropriate principles and consistent with the liberal economy and especially the rehabilitation of economic agents and the adaptation of all economic sectors to a certain rigor and economic discipline, far from antecedent practices based on economic dirigisme.

In this sense, a new industrial policy was built and recommended for this economy, convinced of the need to diversify the industrial portfolio and the obligation to turn to other industrial sectors more complementary and substituting with the energy sector, in order to achieve a balance within the sector and in a second phase a possible contribution in the national economic growth.

Feeling a real danger and risk of deindustrialization, especially in these painful times for the national economy (with the loss of oil revenues), the concerned ministry (the Ministry of Industry and Mines) launched in 2016 a new roadmap for the revival of this sector, with a goal of exit from lethargy and decline observed during two decades, and in accordance with the orientations of the economic decisionmakers, from the moment that the agricultural sector seems 
to display a certain availability in this direction.

So, and according to this ministry, "Algeria's new industrial strategy is based on the following four main axes:" [15]:

1. Choice of sectors to promote.

2. Sectorial deployment of the industry.

3. Space deployment of the industry.

4. Industrial Development Policies.

For the first axis, it is a question of identifying the branches of industry that can bring in more extra and lead for the sector, trying to analyze and examine the level of competitiveness, endurance and efficiency of these branches through its strengths and weaknesses, in order to avoid errors and shortcomings recorded during subsequent experiments.

For the second axis, it is much more a question of a tactic that will address three essential elements, namely: The valorization of natural resources, the densification of the industrial fabric and the promotion of new industries, the latter must draw and exploit the technological availability, including innovation and the latest technical tools.

For the third axis, it is more a rehabilitation of industrial areas according to new standards and technological forms, to establish bridges and synergy between new industries and forms and specificities of these areas.

Finally, the last line is more global and contributory in this new strategy, as long as it is a question of establishing a more seasoned and refined sectorial policy, covering and overseeing four fundamental directions, among others: An upgrade potential and ready companies for this type of strategy, the implication of an innovation policy and a national system, the appeal to foreign operators through FDI more committed and experienced in this kind of policies, and finally the use of national skills through another human resources training policy.

Let's start with H. DJOUFELKIT who thinks that this strategy comes from a need to review the industrial development trajectory in this country, as long as the manufacturing industry seems to be in a free fall $(5 \%$ in GDP and $7 \%$ in employment), insisting on the overhaul of an institutional economy to be able to accompany this policy [8].

Concerning O. BOUKHDOUNI, this approach is more designed in a sense to rehabilitate this crucial sector for the national economy, bringing some reasons and explanatory factors of this strategy, among others: [9]

1. A probable reconquest of the domestic and regional markets.

2. Better exploitation and use of natural gas.

3. The need to rehabilitate the industrial park.

4. Greater interest and concern for high value-added industries.

For the author, this new vision of industrial development through the NSI 1 requires some conditions, such as the absolute improvement of the business climate, the use of financial and capital markets (which the absence is strongly

$1 \mathrm{NSI}=$ New Industrial Strategy felt and deplored) and especially the obligation for national companies to upgrade in order to be able to arm themselves with a certain international competitiveness in tough times.

For its part, A. GHOUFI (5) is concerned about the decline in industrial production (which reached a rate of $2.3 \%$ in the first half of 2015), and more particularly for, once again, the manufacturing industry, interested, for such initiative, in the following axes: [5]

1) Support for the competitive capabilities of national companies (as long as the country is pleased to have more than one million medium-sized enterprises).

2) Valorization of local and national skills.

3) Enlargement and deepening of national production.

Finally, another report converges to the fact that the industrial sector suffers from a certain complication and delicacy in its launching and revival, requiring, in fact, the implementation of a new strategy which will have to work and look to certain objectives such as: Upgrading, collaboration and coordination between SMEs / SMIs, the creation of a subcontracting market, industrial innovation and others, showing, in this way, that the strategy invoked and initiated by the Algerian state must take into account the new torments of the international economy. [12]

This reinforces the idea that the industrial world, through this strategy, is required to follow the most recent and modern technological developments (where the role of a monitoring system is more than recommended and desired) in order to set up a new industrial recovery route without giving rise to additional and heavily costs.

It is clear that this new form of industrial development is part of the need for the government to start an industrial diversification by opting for industries that can complement and replace in front of undesirable events, and also for the establishment of a long-term policy that is not always dependent on the pace of change in oil prices and which will involve the most successful industrial sectors, carrying real promises of growth and development and especially innovative.

Renewing a particular and more pronounced interest in the mechanical, electronic, steel, agro-food, wood, textile and other industries, this new policy attempts to recover and exploit the advantages that can be derived from them, taking into account the fact that the latter have contributed to the good industrial dynamics of the 1970s and have been a boon for economic decision-makers to build a large and flourishing industrial fabric.

In this perspective, some national economists 2 have insisted that Algeria, through this new policy, must put in place a vision directed towards a global and international industry, knowing, perfectly, that the latter is characterized by technological and innovative inclinations particularly useful and recommended for a leading industry, which will have to be taken into account, warning that "it is through the quality

2 Indeed, three renowned economists, in this case A.MEBTOUL, M.PREURE and L.GOUMIRI, contributed in a synthesis entitled: "In the face of global changes, the strategy of the sectors in Algeria must fit within 'a strategic vision', Algiers, January 2013. 
approach, that the industrial practice, the industrial culture and therefore the 'productive efficiency'[3], thus insinuating that new industrial practices must be more targeted, selected and highly processed in a logical framework of preference, in an industrial world that only exist thanks to new international industrial engineering.

According to these authors, some industrial sectors deserve attention in order to be more competitive (although this may seem difficult to achieve in the immediate future), among others, the mechanical industry, building materials, pharmaceutical, agro-food, subcontracting, leaving, as a result, initiative and primacy to this new strategy to properly conduct appropriate and adequate actions, taking into account, of course, some parameters that are deemed necessary and required for such a large project:

1. Availability of human capital.

2. A consequent technological redeployment.

3. An appropriate and relevant institutional economy.

4. Industrial training.

5. A more enterprising and tough state in its implications and contributions in the strategy.

6. A national economic enterprise rid of its obsolete and inappropriate types of management.

7. An industrial mix-up focusing on the need to introduce new techniques and a common and convergent vision on the NSI.

4) Back to the financial nightmare

Following the same impacts during the crisis of the collapse of the price of the barrel in 1986 which has lost revenues eagerly sought and required for the continuation of the efforts of the socio-economic development, there is another similar crisis with a sudden fall of these prices (from an average price of $\$ 110$ between 2007 and 2013 to another between $\$ 27$ and \$ 30 in the years 2014 and 2015), which gave birth to some hiccups for the national economy, among others:

a) A trade deficit of nearly $\$ 14$ billion in 2015 .

b) The import coverage rate went from $107 \%$ in 2014 to only $73 \%$ in 2015 .

c) The deficit of the public treasury went from 413 billion DA at the end of February 2015 to 1404 billion DA at the end of February 2016.

d) Budget revenues decreased to 714 billion DA in 2016 against 895 billion DA in 2015 .

e) Public expenditures increased, for their part, to 2040 billion DA during the first two months of 2016 against 1222 billion DA in 2015 (for the same period).

f) A budget deficit of nearly 33 billion DA according to the financial law 2016.

g) The FRR3 is fueled at almost $\$ 17$ billion against a range of $\$ 40$ to $\$ 50$ billion two years ago.

h) According to IMF forecasts 13, gross domestic product (GDP) will be \$ 166 billion against \$ 172 billion in 2015.

i) The current account deficit will have to reach more than

3 FRR=Fund of Regulatery Revenues
\$ 28 billion in 2016 compared to \$ 27 billion in 2015 .

According to this report, the foreign exchange reserves of the country will have to reach nearly 113 billion (for a coverage of nearly 22 months) against 143 billion $\$$ in 2015 .

This dark picture is also worsened by an unemployment rate that sits around $11 \%$ after having skirted the bar of $-10 \%$ over the last three years, and also an inflation rate that flirts with the $6 \%$ against an average of $3 \%$ for the last years.

Thus, the sharp fall in oil prices has created a veritable cascade of unfortunate consequences for the national economy, at a time when economic decision-makers have been banking on macroeconomic forecasts that are quite encouraging, such as an economic growth rate of $4.6 \%$, foreign exchange reserves of more than $\$ 210$ billion, and especially the launch of the five-year program 2015/2019 with an amount of nearly $\$ 282$ billion (a staggering amount it must be admitted).

Speaking of financial contraction, and according to the country's monetary authorities, the national economy drew 35 billion from the regulatory fund and other financial sources just for the year 2015, waiting for the end of the year ongoing, demonstrating, thus, all this fragility and financial vulnerability of the State, at a time when the international economy complains of a worrying and pessimistic deceleration and economic decline for the years to come, hence a major risk the emergence of financial contraction on an international scale and the difficulties of borrowing for certain states, as is envisaged for the Algerian case.

Our concern is justified by the fact that the financing of projects, programs and policies is almost connected to oil revenues, which themselves are linked to the good performance of international markets, and these latters have become, so much, unpredictable and unsustainable, especially since the new industrial strategy is designed according to international and universal standards, and therefore more demanding in terms of financial contributions, which encourages a serious reflection on the chances of financing this policy.

Of course, the financial situation is not as catastrophic as one thinks of the moment that the international reserves and the fund of regulation of the receipts can allow some margins of maneuver, but how much will it last?

In its latest report, this financial institution, even if it does not seem too worried and panicked about the critical phase of the Algerian economy for the immediate future, remains relatively reserved on the forecasts of the coming years if prices will remain stable and stagnated around a price of between \$ 50 and \$ 60, warning that "budgetary difficulties" are due in particular to the level of expenditure and the fall in revenue rates. In fact, Algeria needs a barrel at nearly $\$ 100$ to reach equilibrium, according to a chart in the report. However, the forecasts of the BM are based on a barrel of oil around 50 dollars. [14]

Synthesis of many interventions, it seems that the financial contraction is present and heavy in the national financial sphere, and this is perfectly argued and explained according to the following parameters: 
The real and justified possibilities and probabilities of a rapid and immediate depletion of the available financial resources (international reserves, revenue regulatory funds, dividends on international financial investments, etc.).

The confirmation by the State of the continuation of the social expenses, as long as the social transfers (a too budgetary and spending sector) went from 254 billion DA in 1999 to 1731 billion DA in 2015, in a financial situation which pleads more for the rationality and the control of the public expenses for lack of adequate and reassuring public revenues.

The need (strongly recommended and required) for a restoration of a balanced budget, as long as for the year 2016, it is expected public revenues of the order of $\$ 45$ billion against public expenditures in the amount of $\$ 75$ billion, so a budget deficit of the order of $\$ 30$ billion will imperatively fill and solve, meaning, in the same time, strong pressure on the treasure in this direction.

The fear that oil prices will stagnate and stabilize at a level not too desirable and claimed by the government, because this will lead, inevitable, to external debt, as was the case in 1986, with all the unfortunate consequences that caused.

The confirmation of a reduction in public spending (while these must play a decisive role in the financing of economic projects such as that of industry) of $9 \%$, signifying, as a result, some financial turmoil in the future, knowing that the industrial strategy will not be the only one to finance.

Large and disturbing international financial disruptions are already looming on the horizon, particularly for the rentier economies, as is the case with this economy, which gives rise to serious misgivings about the anticipated financing.

Regarding the latest news, it seems that the Algerian economy has suffered deeply with the COVID-19, added to the decline of oil prices which attain nearly $20 \$$ last year, indicating that the growth rate has achieved a rate of minus $5.5 \%$, a growing rate of public debts with more than $75 \%$ in 2022 , a decline of the rate of current balance of $26 \%$ of the GDP, and the same situation of the rate of exchange which is expected to attain a rate of one dollar to 150 Algerian dinar in 2022.

\section{Results and Discussion: What Kind of Funding to the New Industrial Strategy in such an Economic and Financial Situation}

This form of interrogation seems to us to be well placed and appropriate because the Algerian economy is giving little convincing and confident signs for the next schedules, especially when all international financial institutions, international economic organizations, think thanks and others, are fearing some complications and difficulties in reassuring and comforting budget recovery, at a time when international economic indicators do not show signs of optimism and a promising future.

Reading a few written on this subject, it is now clear and certified that the question that arises with acquitted does not concern the source of the financing (state, primary banks, foreign investments, private sector, or others) but how one ensures the financing of such a strategy that concerns nine vital sectors and industrial zones, not to mention the energy sector and other infant industries?

Knowing perfectly the contours of this economy and the reactions of economic leaders and decision-makers, in addition to a certain chilliness and greed of domestic private entrepreneurs when it comes to financing issues, the choice of the state (and again the public treasury which is concerned) does not suffer from any anomaly or incoherence to carry out this operation, having in mind that the launching of such a policy was agreed at the moment of a certain financial ease and the insurance of a financing capacity that has affected other sectors and economic domains.

This is confirmed by the concerned ministry with a financial contribution of $\$ 180,000.00$ and another from UNDP with \$174,270.00, confirming, as well, that the Algerian State is well subject to ensure regular funding and permanent, if we want to prevent the sector invoked falls again, in the crooked and abandon, at a time when the speech on the need for economic diversification is amplified and questions regarding food security, energy security, and manufacturing security arise with great emphasis and attention.

It is true that the support of the European Union for this project can be welcomed, as it was pointed out by the representative of the institution, who states that "a program to support industrial diversification and promote improvement of the business climate in Algeria is to be launched before the end of the current year and will be jointly financed by the European Union (EU) with 17 million euros and by the Ministry of Industry and Mines with 1.7 million euros ", but, notwithstanding the amounts declared, this does not settle the affairs of the State, as long as this financial support is subject to counterparts and concessions that the local government must provide and propose to this international institution.

It must remembered the disappointment and desolation of the Algerian authorities of the economic partnership established and initialed with the Union since 2005 and which has much more benefited the European economies than this country, especially when the industrial sector relegated to undesirable position. This raises some doubts and suspicions about the regularity and continuity of such funding, and also that this community is facing, recently, some economic and financial concerns (admitted by the ECB (4).

The implementation of the new industrial policy faces, from its launch, serious doubts about the available financial which the State promises to implement, in addition to the elements and parameters mentioned above, there are other sources of concern and fear, for example, the freezing of several industrial projects that should add to this strategy, as announced by the officials concerned.

$4 \mathrm{ECB}=$ European Central Bank 
Different scenarios are envisaged and designed for the national economy, particularly the possible and probable oil revenues, by different international financial institutions which all converge towards certainty that if the price levels of the barrel remain around $\$ 50 / 60$ for the next five years, a balanced budget will be difficult to fill, not to mention a mobilization of public savings for the consolidation of financing of economic projects (like the industrial development).

Thus, the IMF (again) insists on this question of the vulnerability and fragility of this economy, saying that "the budget deficit will widen, the public debt, almost nil today, could increase to reach three quarters of the domestic product gross, the foreign exchange reserves will shrink to 70 billion dollars in 2020, "[6], a level that is not comfortable for a country like Algeria". This could happen to Algeria if "the current economic policies remain unchanged" and "fiscal consolidation" is not done ", a way to play the card of transparency and realpolitik and insist decision-makers not to skimp on the financial means available to succeed in this industrial strategy.

The Algerian economy is inscribed in the register of monoexporting countries, the price of oil is determined exclusively by international markets and the most influential states, oil revenues are denominated in dollars (according to the evolution of this currency) and main imports are determined in Euro (also depending on the evolution of the latter), which leaves little leeway for this State to take over the financing of the economic strategies launched before, especially when several projects are in waiting list like the very serious questions of housing and education.

Far from us any temptation of pessimism, skepticism or fatalism, our professional conscience leads us to a certain caution and reserve on the future of the industrial strategy for the case of this economy, because the available figures speak for themselves as well the statements of the public authorities themselves (headed by the Prime Minister), without ignoring the reports of the international financial institutions, as long as it is a policy of rehabilitation of this sector and the need for a start of industrial growth at a time when there is a certain economic sluggishness.

A local think-tank warns about the country's upcoming economic and financial deadlines, stressing, in passing, that "if the current status quo continues, Algeria's foreign exchange reserves will be consumed on the horizon. 2025 and the public debt could reach 80 billion dollars at this date "[7], which translates the urgency for the initiators of the NSI to insist on the search for the most appropriate and less expensive sources of financing, some economists even speak of a return to external debt, because there is indeed a financial contraction that must be negotiated in this direction.

\section{Conclusion}

The formulation, implementation and development of a strategy imply, inevitably and undeniably, a logistic and financial platform according to the dimensions and contours of it, because any strategy is based on two key factors: The funds available and the time and delay.

The new industrial policy, as elaborated and traced by the initiators, is intended to be more entrepreneurial, gradual and centered on a renewal of the manufacturing and nonhydrocarbon industries, according to the new orientations of politico-economic decision-makers who have noted a blind dependence and without limit to the hydrocarbon industries which proved to be powerless and unable to put the local industry back on track of development and growth, especially since statistics have shown limitations, even if it is the industry out -hydrocarbon which contributes more in the national product (despite the rate considered very insufficient and sometimes insignificant).

Certainly, some feel a willingness of decision makers to put this important sector back on track and put it back into the real economic sphere has been confirmed, but it is wondering if the current and actual economic situation will not distort this approach, as long as the indicators and others signals, which certainly do not yet emit distress and panic, indicate measures of prudence, foresight and rationality in matters relating to the financing of projects and economic programs.

Based on theoretical and literary arguments, it is considered that the new industrial strategy will not escape or avoid some financing problems, despite the assurances (quite justified and logical of the Ministry). There are no serious grounds for comfort or assurance on the sustainability of the financing of this approach and it is still necessary to find the necessary non-hydrocarbon funds that can guarantee such financing, in a tense and disrupted international financial situation.

The financial contraction exists and is well felt, starting from the fact that the foreign exchange reserves undergo quite serious cuts since the fall of the price of the barrel (which lost more than $50 \%$ of its value), as well as the promising regulatory fund (FRR), which has seen a fairly worrying melting in the last few months, and especially prospects for a rather compromising and dubious price recovery for the barrel5, which does not bode well for public finances, not to mention the need budget rebalancing and continued funding of ongoing projects.

Financial options are well announced and put back on the circuit, like a return to external debt or the use of the bond to ensure the financing of this operation, it sound a well-oiled economic mechanism on the financial institutions side, but this is also complicated for two main reasons:

1) The risk of a return to the financial nightmare of the 1986 oil crisis with all the consequences and impacts experienced.

2) The risk that the State itself will no longer be able to finance these commitments and also the regular financing of the strategy undertaken.

What is the promise of a State in the face of financial

5 Well-designed scenarios indicate that, in the best of times and in a good economic climate, these prices should not exceed $\$ 60$ to $\$ 70$. 
strangulation and bottleneck?

\section{References}

[1] A. ALBERT and MAXIME A. CRENER, "The New Industrialized Countries: Strategies for Industrial Development-the Case of South Korea and Brazil," International Studies, Vol 13, No. 2, 1982.

[2] A. BOUZIDI, "Industrialization and industries in Algeria", in the Algeria of tomorrow: taking up the challenges to win the future ", electronic site.

[3] A. MEBTOUL, "Evolution of the structures of the Algerian economy 1967/1980", Volume 1, Algiers, 1981.

[4] A. BOUYAKOUB, quoted in "Where's Algeria heading?" By A. MAHIOU and J. R. HRNRY, IREMA, Karthala, 2001.

[5] A. GHOUFI, "Growth Strategies and Industrial Policies: An Analysis of the Algerian Case", Journal of Economic and Managerial Research, No. 6, December 2009, University of Biskra (Algeria).

[6] G. RAVEAUD, "Industrial policies to the rescue of globalization", Revue Alternatives Economiques ", No. 282, July 2009.
[7] J. A. ROBINSON, "Industrial policy and development: Analysis in terms of political economy", Development Economics Review, No. 4, Volume 18, 2010, page 21.

[8] H. DJOUFELKIT, "Annuity, development of the productive sector and growth in Algeria", Working Document, AFD N ${ }^{\circ}$ 64, June 2008.

[9] O. BOUKHDOUNI, "The new industrial strategy in Algeria: Realities and perspectives", journal Economic and managerial researches, $\mathrm{N}^{\circ} 16$, University of Biskra, 2014 (Algeria).

[10] The magazine "Alternatives Economiques", Hors-série $\mathrm{N}^{\circ} 98$, October 2013.

[11] UNIDO report entitled "Report on Industrial Development: Supporting Employment Growth: The Role of the Manufacturing Sector and Structural Change", 2013.

[12] UNDP report entitled: "Support to the implementation of the industrial strategy and the promotion of investments", Algiers, 2012.

[13] The financial institution's report regarding the MOANAP of April 2016.

[14] World Bank Report of June 2016 on the World Economic Outlook.

[15] Various reports from the Ministry of Industry and Mines, Algiers. 